\title{
Power Quality Issues on Distribution System : A Survey
}

\author{
MD Shahabuddin Alam \\ M. Tech Scholar \\ IES College of Technology, IES University \\ Bhopal (M.P.), India \\ salam9501@gmail.com
}

\author{
Jyoti Bansal \\ Asst. Professor \\ IES College of Technology, IES University \\ Bhopal (M.P.), India \\ jyotig1979@gmail.com
}

\begin{abstract}
Improving the quality of energy in distributed generation is a rapidly growing, challenging, and interesting area of modern times. In recent decades, a large number of techniques have been developed to improve energy quality. This article attempts to comprehensively examine a wide range of methods for improving power quality in distributed generation. This includes the use of active filters, Dynamic Voltage Restorer, DSTATCOM, reactive power compensation techniques, and an unmodified power quality conditioner. In this test, all of these methods are examined with power quality parameters such as reverse power flow, voltage stability, and current harmonics. This document describes energy quality problems and possible effects on the distribution system due to a grid-connected photovoltaic system.
\end{abstract}

Keywords: UPQC, DSTATCOM, distributed system, VAR.

\section{INTRODUCTION}

Energy quality is an important element of the smooth functioning of consumers. In recent times, environmental influences and growing energy needs have led the electricity grid to evolve towards decentralized production. It is known that when installing distributed generation sources, power quality problems such as reverse current flow, voltage instability, and voltage or current harmonics are inevitable. To improve the voltage quality, the Dynamic Voltage Restorer was used as an effective device to protect voltage sensitive loads from voltage instability. The DVR places three single-phase voltages of appropriate size and phase in series with the supply voltage through the booster transformer to achieve power quality. Photovoltaic systems are increasingly popular. In [1], an inverter is used to feed the grid with the PV interface with active power. The Fuzzy Logic controller is used to control the tracking of maximum performance points. The active power shunt filter uses control technology to remove harmonics from the mains current and increase the power factor. The production of photovoltaic energy is more dependent on weather conditions and is an interruption that affects the grid and cannot be ignored.
STATCOM is a static compensator is a new device that performs reactive power compensation closer to the load [2]. By adjusting the amplitude and phase of the supply current / voltage to the PCC, reactive power compensation can be achieved, thereby achieving voltage stability. In [3], the solar photovoltaic efficiency was studied as a function of the variation of the generated radiation and the operation of the photovoltaic-based inverters. The author attempted to mitigate the effect of solar generation on the low voltage grid through the inverter's VAR control strategy.

Many people have had different ideas for solving the power quality problems associated with distributed generation. None of the previous articles related to distributed generation have addressed the problem of reverse energy flow in the LV power grid.

\section{LITERATURE REVIEW}

Emad Jamil et al. [4] this paper presents energy quality improvement for effective energy transmission in a matrix incorporated sunlight based photovoltaic-wind half and half system. The half and half system speaks to a sustainable power park dependent on a photovoltaic energy creation system and a breeze energy transformation system. The system encounters regular breaks in $\mathrm{AC}$ loads and force age from inexhaustible tasks. This prompts a crisscross in receptive force and postures issues with voltage shakiness and force quality.

S.Premalatha et al. [5] In this article, an inverter with a matrix interface is planned, which goes about as a force converter to gracefully the network with power from sustainable power sources and a Shunt Active Power Filter (SAPF) to limit music and impartial charging current. Another control approach called Unit Vector Template Generation (UVTG) was created for SAPF and introduced in this record. The reenactment was performed for a three-stage four-wire dispersion system (3P4W). 
Pragya Patel et al. [6] this article shows the ever-expanding interest for power that the advanced force system needs to extend and modernize. The most recent advancements in the dissemination system and industry rely upon gadgets dependent on power hardware. What are the principle wellsprings of nonstraight loads and sounds in the electrical organization Helpless force quality can prompt voltage drop, expanding, symphonious age and gadget disappointment because of serious current, voltage and recurrence irregular characteristics. It is critical to know about the nature of the eating regimen. This article gives a diagram of intensity quality issues, their issues, and strategies to address them.

Wael S.Hassanein et al. [7] This article proposes an Artificial Neural Network Controller (ANN) Dynamic Voltage Restorer (DVR) to improve the exhibition of a self-sufficient crossover environmentally friendly power system serving another network in Egypt. The cross breed system comprises of three environmentally friendly power sources, in particular photovoltaic sun based cells, a lasting magnet simultaneous generator dependent on wind turbines and energy units. These three sources are associated with a typical halfway circuit by three lift converters, one for each source. The basic middle circuit is associated with the AC side through a DC/AC inverter. The ideal size of the three inexhaustible sources offered is determined utilizing the HOMER programming bundle. Control of the DVR is accomplished by changing the charging voltage under different strange working conditions.

Akshay S. Shirbhate et al. [8] this article examines the force quality issues brought about by changes in climate conditions, for example, sun powered radiation and the adjustment in the heap associated with the system. These organization quality issues, for example, voltage variances, voltage contortions and sounds at L.T. Lines are additionally created on the PCC by source and burden. This article gives a review of intensity quality issues and relief method when utilizing dynamic channels.

\section{Distribution Static COMPENSATOR}

DSTATCOM may be a custom shunt connected power supply device designed specifically for power factor correction, current harmonic filtering, and load balancing. It also can be used for voltage regulation on a distribution bus. It's often mentioned as a shunt or parallel active power filter. It consists of a voltage or current source PWM converter Fig 1. It functions as a current controlled voltage source and compensates for current harmonics by injecting the harmonic components generated by the load but 180 degrees out of phase. With an appropriate control scheme, DSTATCOM also can compensate for the low load power factor. When STATCOM is applied within the distribution system it's called DSTACOM (DistributionSTACOM) and its configuration is that the same, or with small modifications, oriented to a possible future amplification of its possibilities within the low and medium voltage distribution network, by implementing the function in order that we will describe as flicker damping, harmonic filtering and full and short break compensation.

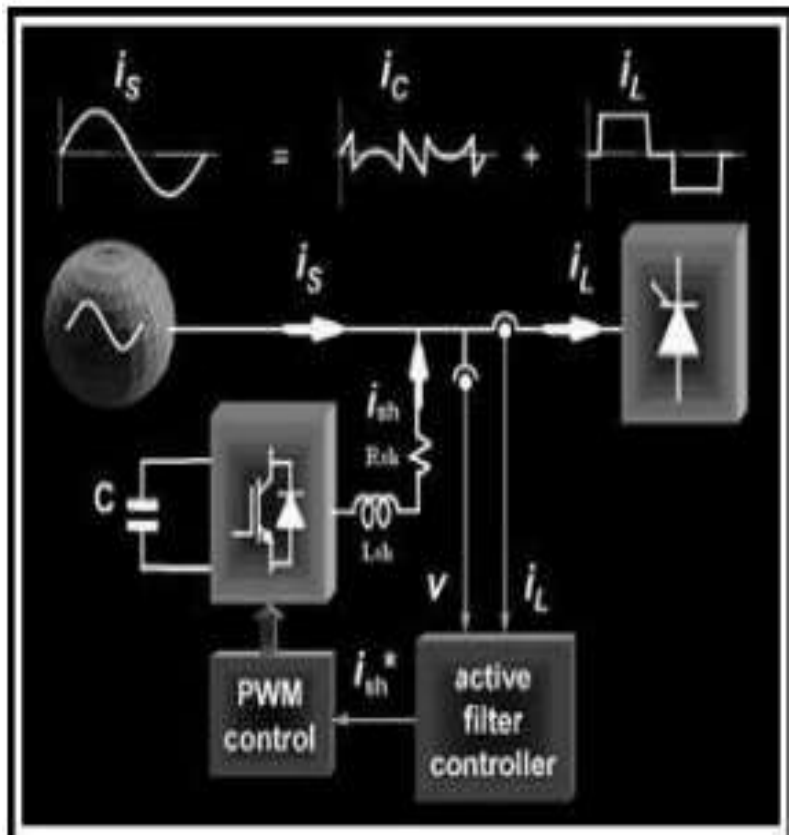

Fig. 1: System Configuration of DSTATCOM

\section{Power Quality Problems}

\section{A. Poor load power factor}

The ratio of the particular power flowing over the load to the apparent power within the circuit is named the facility factor of the facility system. it's a really important term within the electrical system. the power of the circuit to operate over a period of your time is named real power and therefore the product of current and voltage is named apparent power. In power systems, due to the varied uses of semiconductor devices or non-linear load, the waveforms of voltage and current are distorted, which makes the apparent power greater than the important power, and low power factor in the circuit is achieved. When the facility think about an electrical network is low, the quantity of current flowing within the circuit will attract quite one load with a high power factor for an equivalent transmitted useful power. When the circuit features a high current, the energy loss within the circuit is bigger and requires larger cables and other electrical devices. [9] 


\section{B. harmonics}

Harmonics are sinusoidal voltage or current components with a frequency that is an integer multiple of the supply frequency. Distortion means changing the original shape of a sound waveform in the image of an object or another form of information and representation. Harmonics are also a type of distortion that changes the voltage and current waveform of the fundamental supply frequency. Various non-linear loads, power semiconductor components, fluorescent lamps, variable speed drives, PC, etc. they are harmoniously generated in the power grid. This creates various negative effects on the system, reducing system efficiency, plant malfunction, plant aging, machinery overheating and failure, overloading of power factor correction capacitors and power transformers [10].

\section{Notching in low voltage}

When current is converted from one phase to another, a disturbance in the voltage waveform is known as voltage notches. This is a type of disturbance in power quality. A voltage notch interrupts the stress waveform and excites the natural frequency of the system, which is usually where these frequency ranges are located, which is a high frequency range that introduces many harmonic and non-harmonic frequencies higher than those found in a higher stress system. The excision frequency generates high frequency oscillations in the voltage of the converter circuit, logic and communication circuit, overload in electromagnetic filters [11].

\section{D. voltage imbalance}

The voltage imbalance or unbalance is the ratio between the maximum deviation of the average of the three-phase voltage and of the three-phase current with respect to the average of the three-phase voltage and of the three-phase current. Many regions are responsible for voltage imbalance, such as: large singlephase distribution transformer in the system, power transformer ground fault, open transformer banks with delta connection, uneven impedance in cable conductors power supply, heavy reactive single phase load such as welding machines etc. [12].

\section{E. Disturbance of supply power}

A fully sinuous wave of voltage and current is required for good quality power in an electrical system. However, interruption, distortion, failure, swelling, flicker, over voltage, under voltage, etc. they are the power disturbance that is responsible for different types of power losses in the system. A short-term power outage trips the relay due to heating in the system, combustion power, damage to semiconductor components, and many problems.

\section{Possible Effects on Distribution System Due to GRID CONNECTED PV SYSTEM}

In the renewable energy source, the photovoltaic system is a more reliable energy source. It, therefore, arouses considerable commercial interest. For a distribution network, connecting a distributed photovoltaic system to a distribution network can lead to several operational problems. The severity of these problems varies according to the percentage of penetration of the photovoltaic system and the geography of the installation. Knowing the potential impact of grid-connected distributed PV systems on distribution networks can help you find viable solutions before practical, real-time deployments. This section contains an introduction to the possible effects that a PV system can have on a distributed system.

A. Photovoltaic surge systems are designed to take full advantage of solar energy. This only happens when the system is operating with a power factor close to unity. In this case, the reactive power flow of the system can change due to the active power of the photovoltaic system being fed into the public grid. Due to the lack of reactive power, the voltage of neighboring buses can therefore be increased [13]. The generated overvoltage can have a negative effect on the operation of the supplier and the customer.

B. Harmonics are a serious power quality problem caused by the use of power electronics in photovoltaic systems such as inverters that convert direct current to alternating current. Due to the inverter, the harmonics generated can cause series and parallel resonances, overheating of the transformer and capacitor bank and the reliability of the power supply systems can decrease due to the malfunction of the protection devices, inverter and PWM generator. [14].

C. Power fluctuations Fluctuations in the output power of photovoltaic systems are one of the main factors that can cause serious operational problems in the public grid. The variation in solar radiation occurs due to the movement of the clouds and can last for minutes or hours, depending on the wind speed, the type and size of the passing clouds and the area covered by the photovoltaic system. These fluctuations in solar radiation cause fluctuations in performance. And this power fluctuation can lead to unacceptable voltage fluctuations, voltage flickering, power fluctuations in the lines as well as overloads and under loads. [15]. 
D. Frequency fluctuations Frequency is the most important factor in power quality. Frequency fluctuations can occur due to an imbalance between the power consumed and the power produced. The small size of photovoltaic systems means that frequency fluctuations are negligible compared to other resources based on renewable energy. The increase in penetration levels and the number of distributed photovoltaic systems becomes more serious for these problems.

E. Inrush Current The difference between the grid voltage and the PV system voltage can cause an inrush current to flow between the PV system and the power grid at the time of connection and drop exponentially to zero. Annoying travel, thermal stress and other problems can occur due to the inrush current [16]-[17].

These problems arise due to changes in grid-connected photovoltaic systems. These problems can be eliminated. Harmonics, surges due to excessive reactive power in the network, voltage fluctuations due to conventional methods such as passive filters. But in traditional methods or passive filters have fixed areas to eliminate the problems. The value of inductors and capacitors is fixed. For this reason, it can work for a fixed range of harmonics. It doesn't work for reactive power. During voltage fluctuations, no over voltages can be introduced into the system or taken from the system. If the value of the inductance and capacitor is increased, the network impedance may change. So this creates other problems. With this active filter, the power quality can be improved by eliminating these problems. It covers many system problems caused by system generation and usage.

\section{CONCLUSION}

Different techniques have proposed various techniques for improving the quality of electricity with distributed energy sources to produce electricity. Various techniques for alleviating power quality problems include Dynamic Voltage Restorer, various types of filters to remove harmonics, STATCOM, and DSTATCOM. Reverse current flow is one of the major power quality problems facing the power system today with PV as a distributed power source. This paper describes energy quality problems and possible effects on the distribution system due to a grid-connected photovoltaic system.

\section{REFERENCES}

[1] Hamad, M.S, Fahmy, A.M, and Abdel- Geliel "Power Quality Improvement of a Single-Phase Grid- Connected PV System with Fuzzy MPPT Controller", 2013 IEEE.

[2] Hui Li, Hao Zhang, "Control and Simulation of Grid- connected PV System with DSTATCOM", 2014 IEEE.
[3] Solomon Oyegoke, Yehdego Habtay, Spyros Skarvelis- Kazakos, "Contribution of Inverter based Photovoltaic generators to power quality at Low Voltage", 2015

[4] Emad Jamil, Salman Hameed "Power quality improvement of distribution system with photovoltaic and permanent magnet synchronous generator based renewable energy farm using static synchronous compensator" July 2019 Sustainable Energy Technologies and Assessments 35(C):98-116

[5] S.Premalatha, Subhransu SekharDashDr. "Power Quality Improvement Features for a Distributed Generation System using Shunt Active Power Filter" Procedia Engineering, Volume 64, 2013, Pages 265-274.

[6] Pragya Patel, Dharmendra Kumar Singh "A Review on Power Quality Improvement Issues, Problems \& Their Effects with Suitable Corrective Methods" International Journal of Engineering Research \& Technology (IJERT), Vol. 3 Issue 10, October- 2014

[7] Wael S.Hassanein, Marwa M.Ahmed "Performance improvement of off-grid hybrid renewable energy system using dynamic voltage restorer" Alexandria Engineering Journal, Volume 59, Issue 3, June 2020, Pages 1567-1581

[8] Akshay S. Shirbhate, Prof.Suhas D. Jawale "Power Quality Improvement in PV Grid Connected System by Using Active Filter: Review" International Journal of Advanced Research in Electrical, Electronics and Instrumentation Engineering, Vol. 5, Issue 2, February 2016.

[9] 5)Jain Sandesh, Thakur Shivendra Singh and Phulambrikar S.P. "Improve Power Factor and Reduce the Harmonics Distortion of the System" Research Journal of Engineering Sciences ISSN 2278 - 9472 Vol. 1(5), 31-36, November (2012)

[10] 6. Mr. Suvas Vora, Mr. Dipak Bhatt " A Comprehensive Review of Harmonics Effects on Electrical Power Quality" International Journal Of Engineering Development And Research ISSN: 2321-9939

[11] Reza Ghandehari, Abbas Shoulaie "Evaluating Voltage Notch Problems Arising from AC/DC Converter Operation", Vol. 24, SEPTEMBER 20092111

[12] A A Ansari, D M Deshpande "Investigation Of Performance Of 3-Phase Asnchronous Machine Under Voltage Unbalance" Journal of Theoretical and Applied Information Technology Vol6. No1. (pp 021 026)

[13] R.A. and J. Ventre," Photovoltaic systems engineering," CRC,2004

[14] IEEE Working Group on Nonsinusoidal Situations, "Practical definitions for powers in systems with nonsinusoidal waveforms, unbalanced loads: A discussion," IEEE Trans. Power Delivery, Vol. 11, pp. 79-101, Jan. 1996.

[15] Bhim Singh, Kamal Al-Haddad and Ambrish Chandra," A Review of Active Filters for Power Quality Improvement," in IEEE transactions on industrial electronics, vol. 46, NO. 5, October 1999.

[16] C. K. Duffey and R. P. Stratford, "Update of harmonic standard IEEE519: IEEE recommended practices, requirements for harmonic control in electric power systems," IEEE Trans. Ind. Applicat., Vol. 25, pp. 1025-1034, Nov./Dec. 1989.

[17] MasoudFarhoodnea, Azah Mohamed, HussainShareef, HadiZayandehroodi," power Quality Analysis of Grid-Connected Photovoltaic Systems in Distribution Networks ," ISSN 0033-2097, R. 89 NR 2A/2013 